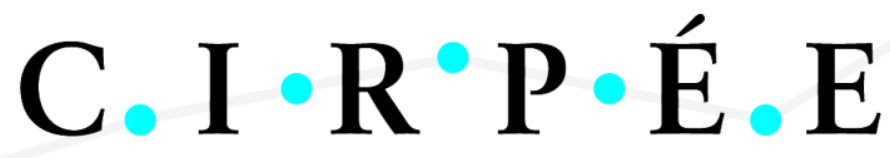

Centre Interuniversitaire sur le Risque, les Politiques Économiques et l'Emploi

Cahier de recherche/Working Paper 15-14

\section{Wage Dynamics and Peer Referrals}

\author{
Vincent Boucher \\ Marion Goussé
}

Mai/May 2015

Boucher: Department of Economics, Université Laval and CIRPÉE

vincent.boucher@ecn.ulaval.ca

Goussé: Department of Economics, Université Laval

marion.gousse@ecn.ulaval.ca

We would like to thank Bernard Beaudreau, Luc Bissonnette, Bernard Fortin, Patrick González and Kevin Moran for interesting comments and suggestions. Vincent Boucher gratefully acknowledges financial support from FRQSC. 


\begin{abstract}
:
We present a flexible model of wage dynamics where information about job openings is transmitted through social networks. The model is based on Calvó-Armengol \& Jackson (2004, 2007) and extends their results outside the stationary distribution, and under observed and unobserved heterogeneity. We present an empirical application using the British Household Panel Survey by exploiting direct information about individual's social networks. We find that the distribution of job offers is positively affected by the employment status of an individual's friends, and that this relationship is stronger for women.
\end{abstract}

Keywords: Labour Market, Peer Referrals, Social Networks

JEL Classification: C33, J31, J46 


\section{Introduction}

Many workforce characteristics (such as wages) are determined outside formal market structures. For example, it is estimated that between $18 \%$ and $45 \%$ of jobs are found using personal contacts (Pellizzari, 2010). A significant portion of wage inequality between different groups, and the persistence of this inequality, may be due to differences in the composition of social networks (Ioannides \& Soetevent, 2006, Fontaine, 2008). Understanding non-market forces governing employment and wages has been a preoccupation for economists, going back to Rees (1966), Granovetter (1973, 1983) and Montgomery (1991, 1992).

In this paper, we present a flexible framework for analyzing how non-market institutions (e.g. peer referrals) affect wages. Our contribution is twofold. First, we contribute to the theoretical literature on network effects in the labour market (e.g. Calvó-Armengol \& Zenou (2005), Cahuc \& Fontaine (2009) and Fontaine (2008)) by extending the results of Calvó-Armengol \& Jackson (2004 2007). Specifically, we show that a natural extension of their results holds outside the stationary distribution, and under observed and unobserved heterogeneity. Second, we present an empirical application using data from the British Household Panel Survey (BHPS) from 1992 to 2008, where we exploit direct information on individuals' friendship networks and the employment status of their friends. We find that the number of employed friends has a significant positive impact on the distribution of job offers (and therefore on wages), and that this effect is stronger for women.

We build on the important contribution of Calvó-Armengol \& Jackson 2004 2007 ) by extending their model to include observed and unobserved heterogeneity. In contrast with most of the literature ${ }^{1}$ our results also hold outside the stationary distribution. This is empirically important since periods of interest often include short-term events such as recessions.

We find that the individuals' wages dynamic is associated. This implies that,

\footnotetext{
${ }^{1}$ See Ioannides \& Loury 2004) for an extensive review of the literature on social networks and the labour market.
} 
conditional on the observables, the wages of any two individuals are positively correlated, across any point in time. We also show that, as time passes, this dependence is strict for any two socially connected individuals, and that the speed at which this dependence spreads can be expressed as a function of the social network. This allows us to describe the impact of a shock to an individual's wage on the overall distribution of wages, at any point in time.

We restrict our analysis to a time-invariant network and we abstract away from strategic network formation considerations, such as in Calvó-Armengol (2004) and Galeotti \& Merlino (2014). However, our empirical strategy controls for part of the potential network endogeneity ${ }^{2}$

We present an empirical application using data from the BHPS from 1992 to 2008. We develop a non-linear dynamic spatial autoregressive (DSAR) model and show that it constitutes a special case of our general framework. An important feature of our model is that an individual's wage is not only dependent on his position in the network, but also on the employment status of the other individuals in the network. We model the dependence on the initial state using random effects, as in Wooldridge (2005).

We find that the number of employed friends an individual has at time $t$ has a positive impact on his wage at time $t+1$, and that this effect is much stronger for women. This result is in line with findings of stronger peer-effects for women (Dieye \& Fortin, 2014, Neumark \& Postlewaite, 1998). Our findings could be explained by better communication and greater solidarity among women, which complements previous interpretations in other contexts, such as social conformism or complementarities. Our findings enrich the existing literature (e.g. Ibarra (1992), Campbell (1988), Hanson \& Pratt (1991) and Marmaros \& Sacerdote (2002) ) that find that women's job networks are relatively "poor" as compared to men's (lower density and "quality") and that social networks contribute to the gender gap in wages and promotions. We find that a small increase in connections to employed individuals has a stronger effect on

\footnotetext{
${ }^{2}$ See also our discussion in section 4
} 
employment outcomes for women than for men.

We contribute to the empirical literature on the effects of networks on the labour market (e.g. Ioannides \& Soetevent (2006)). There are still relatively few empirical works looking at friendship networks. This is mostly due to lack of detailed data. Existing studies use either information on close neighbourhoods (Bayer et al., 2009), or on co-workers' networks (Cingano \& Rosolia, 2012, Dustmann et al., 2011; Åslund et al., 2014). Kramarz \& Skans (2014) analyze the effect of strong family ties on young workers' success in finding jobs. Galeotti \& Merlino (2014) use data on friends and relatives, although they do not observe their employment status.

We use the information provided by the BHPS, which contains direct information about individuals' friendship networks and the employment status of their friends. To our knowledge, Cappellari \& Tatsiramos (2011) is the only paper exploiting this data in a similar fashion. Using a static linear instrumental variables approach, they find that having one more employed friend increases an individual's probability of being employed by $12 \%$. We complement and extend their analysis by proposing a structural non-linear DSAR model in which friends' wages are correlated across time. Our analysis also complements Arulampalam \& Stewart (2009), who also use the BHPS in order to estimate the dynamics of wages and employment using a similar methodology. We enrich their findings by including the impact of the friendship network.

The remainder of the paper is organized as follows. In section 2, we present the microeconomic framework. In section 3 , we present our structural econometric model. We conclude in section 4

\section{Wage Distributions with Network Effects}

We consider an economy composed of a finite set of individuals, $N$. Each individual $i \in N$ is characterized by a time-varying type $\left[\mathbf{x}_{i}^{t}, \varepsilon_{i}^{t}\right]$, where $\mathbf{x}_{i}^{t}$ is observed, but not $\varepsilon_{i}^{t}$. Typically, $\mathbf{x}_{i}^{t}$ will include socio-economic characteristics such as the individual's gender, level of education, and age. We assume that 
the $\varepsilon^{t}$ are independent and identically distributed across time only, so $\varepsilon_{i}^{t}$ and $\varepsilon_{j}^{t}$ may be correlated for a given period of time $t$. Individuals interact in a timeinvariant social network represented by the matrix $\mathbf{G}^{s}$, such that $g_{i j}^{s}=1$ if $i$ and $j$ are linked, and $g_{i j}^{s}=0$ otherwise. For instance, $\mathbf{G}^{s}$ may represent friendships (Galeotti \& Merlino, 2014) or family ties (Kramarz \& Skans, 2014). We denote by $N^{s}(i)=\left\{j \in N: g_{i j}^{s}=1\right\}$ the set of $n_{i}^{s}$ individuals linked to $i$ (i.e. the set of $i$ 's peers). We also denote by $\rho^{s}(i, j)$ the shortest path between $i$ and $j$. The shortest path is the minimum number of links needed to reach $j$ from $i$. If it is not possible to reach $j$ from $i$, we let $\rho^{s}(i, j)=\infty$. If $\rho^{s}(i, j)<\infty$, we say that $i$ and $j$ are "socially connected." At every period $t=0,1, \ldots$, each individual earns a wage $w_{i}^{t} \in W \equiv[b, \infty)$, where $b \geq 0$ is interpreted as social welfare 3

We assume that the evolution of wages can be described as follows:

$$
\mathbf{w}^{t+1}=\varphi\left(\mathbf{w}^{t}, \mathbf{X}^{t}, \varepsilon^{t}\right)
$$

A simple example of 11 is a standard $\mathrm{AR}(1)$ process: $w_{i}^{t+1}=\rho w_{i}^{t}+\mathbf{x}_{i}^{t} \boldsymbol{\beta}+\varepsilon_{i}^{t}$. However, we are interested in a wider variety of economic situations. We present a motivating example below (see Example 1).

It will sometimes be convenient (as in Example 1) to describe the distribution of wages using probability measures. We can denote the conditional probability of $A \in \mathcal{B}^{n}$ at $t+1$, given $\mathbf{w}^{t}$ and $\mathbf{X}^{t}$ as $P\left(\mathbf{w}^{t}, \mathbf{X}^{t} ; A\right)$, where $\mathcal{B}^{n}$ is the standard Borel set on $W \subset \mathbb{R}^{n} 4$ We also define inductively

$$
P^{t+1}\left(\mathbf{w}^{0},\left(\mathbf{X}^{t}\right) ; A\right)=\int_{W} P\left(\mathbf{w}, \mathbf{X}^{t} ; A\right) P\left(\mathbf{w}^{0},\left(\mathbf{X}^{t-1}\right) ; d \mathbf{w}\right)
$$

where we use the short-hand notation $\left(\mathbf{X}^{t}\right) \equiv\left(\mathbf{X}^{0}, \ldots, \mathbf{X}^{t}\right)$. Also note that since $\left(\mathbf{X}^{t}\right)$ is observed, the conditional probability $P\left(\mathbf{w}^{t}, \mathbf{X}^{t} ; A\right)$ defines a nonhomogeneous Markov chain. If we further assume that $\mathbf{X}^{t}=\mathbf{X}$ for all $t$, the model reduces to a standard (homogeneous) Markov chain, as in Calvó-

${ }^{3}$ We assume that wages include any non-monetary benefit or cost associated with an individual's job, so preferences are strictly increasing in wages.

${ }^{4}$ Note that $P$ does not depend on $t$ since the $\varepsilon^{i}$ are independent and identically distributed. 


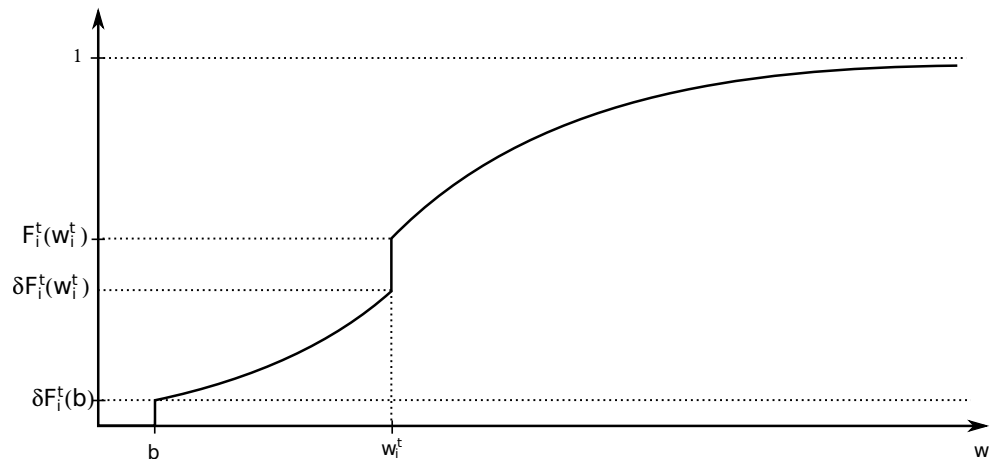

Figure 1: (Example 1) Fix $w_{i}^{t}$, and let $F_{i}^{t}$ represent the cumulative distribution of (direct and indirect) offers for $i$ at time $t$ (so $\gamma$ is implicitly embedded in $F_{i}^{t}$ ). The probability that $i$ becomes unemployed is equal to the probability that he gets laid off and that he does not receive any job offer, i.e. $\delta F_{i}^{t}(b)$. The "jump" observed at $w_{i}^{t}$ is equal to the probability that the individual keeps his current job, which is equal to the probability that he does not get laid off, and that he receives an offer that is less than $w_{i}^{t}$, i.e. $(1-\delta) F_{i}^{t}\left(w_{i}^{t}\right)$.

Armengol \& Jackson (2004, 2007).

Example 1. We present a motivating example for Equation 11. Suppose that, at every period t, the economy is described by the following phases:

1. Each individual is laid off with probability $\delta \in(0,1)$.

2. Each individual receives a job offer with probability $\gamma \in(0,1)$. The distribution of offers follows a (shifted) log-normal distribution $\Lambda\left(\mu_{i}, \sigma\right)+b$, where $\mu_{i}=\ln \left(\alpha w_{i}^{t}+(1-\alpha) x_{i}\right)$ for $\alpha \in(0,1)$. Here, $x_{i}$ can be interpreted as the individual's natural capacity to attract job offers. The dependence on $w_{i}^{t}$ can be interpreted as the signalling effect of the individual's current job to potential employers.

3. Offers are either accepted or further transmitted through the network.

(a) If the offer is less than an individual's current wage, the individual selects one of his peers (independently of his peers' current wages) and sends him the offer.

(b) If the offer is greater than the individual's current wage, the individual accepts the offer (and quits his existing job). He then selects one of his peers (independently of his peers' current wages) and transfers him an offer for his former job.

The fact that $\mathbf{x}_{i}^{t}=x_{i}$ for all $t$ implies that the dynamics of the economy can be described by a homogeneous Markov chain with transition kernel $P_{\mathbf{X}}(\mathbf{w} ; A)$. The marginal cumulative distribution of $w_{i}^{t+1}$ for a given individual $i \in N$ earning $w_{i}^{t}$ at time $t$ is displayed in Figure 1. 
Note that the specification of the dynamics of wages in Equation 1 will generally impose some restrictions on individual rationality. In Example 1, for instance, we assume that individuals accept any job offer that pays a higher wage. This decision is clearly rational in the short run. However, it may be possible that accepting a highly paid job today reduces the prospect of finding an even better paying job in the future. In this case, the naive decision process described in Example 1 would not be rational in the long run. We abstract from these effects by assuming that an increase in wages cannot reduce an individual's future wage prospects 5 Formally:

Assumption 1 (Monotonicity). $\varphi\left(\mathbf{w}^{t}, \mathbf{X}^{t}, \varepsilon^{t}\right)$ is increasing in $\mathbf{w}^{t}$ and $\varepsilon^{t}$.

An equivalent interpretation of Assumption 1 is the following: increasing wages today leads to a better distribution of wages tomorrow, in the sense of firstorder stochastic dominance (FOSD) ${ }^{6}$ Let $\succeq$ represent dominance in the sense of FOSD. Then, we have the following:

Lemma 1. Assumption 1 holds iff $P(\mathbf{w}, \mathbf{X} ; A) \succeq P(\tilde{\mathbf{w}}, \mathbf{X} ; A)$ whenever $\mathbf{w} \geq \tilde{\mathbf{w}}$.

A reference for this lemma can be found in the appendix. Lemma 1 is also useful in order to show that Assumption 1 holds for specific economies, as shown in Example 2.

Example 2 (Example 1 continued). Consider the economy described in Example 17

Suppose that we increase current wages. The properties of the log-normal distribution imply that this results in an increase to the wage distribution of direct offers for the next period, in the sense of FOSD. Since indirect offers are increasing in direct offers and current wages, it also increases the distribution of indirect offers.

Since future wages are increasing in direct offers, indirect offers and current wages, this results in an increase in the distribution of future wages.

\footnotetext{
${ }^{5}$ Note that this assumption imposes more than monotonicity with respect to an individual's wage, as it is also increasing in other individuals' wages. This assumption is also implicitly present in Calvó-Armengol \& Jackson (2004) (lemma 8) and Calvó-Armengol \& Jackson (2007) (lemma A.4).

${ }^{\circ}$ Recall that $\mathbf{w}$ is greater than $\mathbf{w}^{\prime}$ in the sense of FOSD iff $\mathbb{E} u(\mathbf{w}) \geq \mathbb{E} u\left(\mathbf{w}^{\prime}\right)$ for any non-decreasing bounded function $u$.

${ }^{7}$ See the appendix for a formal proof of this discussion.
} 
Note, as discussed above, that the monotonicity of the stochastic process provides a rationale for individuals' behaviour. Since higher wages cannot decrease the distribution of future wages, it is rational for individuals to choose the job with the highest wage.

Since the wage dynamics are monotone, the increase in some individual's wage has a non-negative impact on every individual's wage. However, the effect might not be strict and some individuals' wages may be independent. The dependence structure of $\mathbf{w}^{t}$ is affected by the shape of $\varphi$, as well as by the dependence structure of $\varepsilon^{t}$. In the next section, we discuss the dependence structure of the wage distribution.

\subsection{Dependence Structure}

We first introduce our notion of positive dependence.

Definition 1 (Association). Consider the random vector $\mathbf{w}$. We say that $\mathbf{w}$ is associated if

$$
\operatorname{Cov}(a(\mathbf{w}), c(\mathbf{w})) \geq 0
$$

for all non-decreasing functions a and $c$.

In particular, letting $a(\mathbf{w})=w_{i}$ and $c(\mathbf{w})=w_{j}$ for some $i, j \in N$, we have the following corollary: if $\mathbf{w}$ is associated, then $\operatorname{Cov}\left(w_{i}, w_{j}\right) \geq 0$ for all $i, j \in$ $N$. Association has been used in a very similar context by Calvó-Armengol \& Jackson (2004, 2007). We assume the following:

Assumption 2. $\varepsilon^{t}$ is associated for all $t$.

In particular, Assumption 2 implies that unobserved shocks are positively correlated across individuals. Note that the case where the $\varepsilon_{i}^{t}$ are independent is a special case. An important consequence of this assumption (together with Assumption 1p is the following:

Proposition 2 (Association). Suppose that $\mathbf{w}^{0}$ is associated and that Assumptions 1 and 2 hold. Then, $\left(\mathbf{w}^{t}\right) \mid\left(\mathbf{X}^{t-1}\right)$ is associated, for all $t$.

This result follows directly from the literature on monotone stochastic processes (references are provided in the appendix). Recall that $\left(\mathbf{w}^{t}\right)=\left(\mathbf{w}^{0}, \ldots, \mathbf{w}^{t}\right)$, so 
Proposition 2 implies that association holds for any two individuals, across any points in time.

However, Proposition 2 includes two unwanted features. First, it only describes weak dependence, since any two independent variables are necessarily associated. Second, it depends on the initial state $\mathbf{w}^{0}$, which may be unknown in practice. We address these issues below.

We assume the following technical assumption, which will be convenient in order to simplify the exposition of the model ${ }^{8}$

Assumption 3 (Positive Distribution). For any $\mathbf{w}, \mathbf{X}, P(\mathbf{w}, \mathbf{X} ; A)>0$ for all strictly positive $A \in \mathcal{B}^{n}$.

Note that Assumption 3 holds for Example 1.

We now describe the dependence structure of the wage distribution. Specifically, we want to know which individuals' wages are dependent, and which are not. It will be useful to describe the dependence of the stochastic process using a network structure. However, that network structure may not be the same as the social network structure $\mathbf{G}^{s}$. We assume that the dependence structure can be summarized as follows:

Assumption 4 (Dependence Network). There exists a network $\mathbf{G}^{d}$, called the "dependence network," which is the smallest network such that for all $i \in N$ :

$$
w_{i}^{t+1}\left|\mathbf{w}_{-i}^{t+1}, \mathbf{w}^{t}, \mathbf{X}^{t}=w_{i}^{t+1}\right| \mathbf{w}_{N^{d}(i)}^{t+1}, \mathbf{w}_{N^{d}(i) \cup\{i\}}^{t}, \mathbf{x}_{i}^{t}
$$

Assumption 4 describes two important features of the model. First, the dependence network characterizes the dependence structure of the wage distribution at any point in time. Note that this is done without any loss of generality, since $\mathbf{G}^{d}$ can be the complete network. Also note that $\mathbf{G}^{d}$ is stable through time, since the $\varepsilon^{t}$ are independent and identically distributed. Second, the model is limited to endogenous interactions: an individual is not affected by his peers' types, only by their wages 9

\footnotetext{
${ }^{8}$ See proofs of Propositions 3 and 4 in the appendix, for details.

${ }^{9}$ Note that one can always define $\mathbf{x}_{i}$ as $\left[\hat{\mathbf{x}}_{i}, \hat{\mathbf{X}}_{N^{d}(i)}\right]$ for some initial matrix $\hat{\mathbf{X}}$. In this case, however, any change in $\mathbf{G}^{d}$ leads to a change in $\mathbf{X}$. Assumption 4 allows us to abstract from these unwanted effects.
} 
Note that even if $\mathbf{G}^{s}$ and $\mathbf{G}^{d}$ need not be related, the dependence network will often turn out be a function of the social network. Example 3 highlights the differences between $\mathbf{G}^{s}$ and $\mathbf{G}^{d}$.

Example 3 (Example 1 continued). Consider the economy described in Example 1. We have $\mathbf{G}^{s}=\mathbf{G}^{d}$ since the distribution of (indirect) offers is only a function of the wages of individuals' peers. Put differently, future wages of unlinked individuals are not correlated, conditional on current wages. However, suppose that the network phase is repeated as follows:

3. Offers are either accepted or further transmitted through the network.

(a) If the offer is less than an individual's current wage, the individual selects one of his peers (independently of his peers' current wages) and sends him the offer.

(b) If the offer is greater than the individual's current wage, the individual accepts the direct offer (and quits his existing job). He then selects one of his peers (independently of his peers' current wages) and transfers him an offer for his former job.

(c) Steps (a) and (b) are repeated (for indirect offers) until no offer is accepted.

Contrary to the original game in Example 1, indirect offers can be transmitted through the network (individuals can re-send unwanted offers). Then, the wage distribution of an individual's offers is a function of the wages of their peers, their peers' peers, and so on. Then, the wages of any two socially connected individuals are dependent, i.e. $G_{i j}^{d}=1$ iff $\rho^{s}(i, j)<\infty$, so $\mathbf{G}^{s} \subset \mathbf{G}^{d}$.

An implication of Assumption 4 is that the distance in the dependence network allows us to describe how fast shocks (e.g. information) spread in the economy. Formally:

Proposition 3. Under Assumptions 3 and 4 .

$$
\left(w_{i}^{t} \perp w_{j}^{t}\right) \mid \mathbf{w}^{0},\left(\mathbf{X}^{t-1}\right) \quad \text { iff } \quad \rho^{d}(i, j)>t
$$

See the appendix for a proof. Since the dependence network characterizes the dependence of $\mathbf{w}^{t}$, the shortest path in the dependence network allows us to describe how many periods are needed in order for a shock to spread from one individual to another. Note that if the dependence network is such that $\rho^{d}(i, j)<\infty$ iff $\rho^{s}(i, j)<\infty$ for all $i \neq j$, Propositions 2 and 3 imply that the wages of any socially connected individuals are strictly associated after some 
finite amount of time 10

Note, however, that Proposition 3 suffers from the same limitation as Proposition 2 the dependence on the initial state, $\mathbf{w}^{0}$. We now provide sufficient conditions for the dependence on $\mathbf{w}^{0}$ to vanish asymptotically. We assume the following:

Assumption 5 (Layoff Probability). There exists $\underline{\delta} \in(0,1)$ such that

$$
\underline{\delta} \leq P(\mathbf{w}, \mathbf{X} ; \mathbf{b})
$$

for all $\mathbf{w}, \mathbf{X}$.

This last assumption ensures the recurrence of the stochastic process at state b. Note that Assumption 5 holds for Example 1 , since $P(\mathbf{w}, \mathbf{X} ; \mathbf{b}) \geq(1-\gamma)^{n} \delta^{n}$ for all $\mathbf{w}, \mathbf{X}$.

Let us define the "total variation norm" as $\|P\|=2 \sup _{A \subseteq W}|P(A)|$. Then, the next proposition follows. (See the appendix for a proof.)

Proposition 4. Under Assumptions 3 and 5, and for any $\mathbf{w}^{0}$ and $\tilde{\mathbf{w}}^{0}$ :

$$
\left\|P^{t}\left(\tilde{\mathbf{w}}^{0},\left(\mathbf{X}^{t-1}\right) ; \cdot\right)-P^{t}\left(\mathbf{w}^{0},\left(\mathbf{X}^{t-1}\right) ; \cdot\right)\right\| \rightarrow 0
$$

as $t \rightarrow \infty$. Moreover, if $\mathbf{X}^{t}=\mathbf{X}$ for all $t$, there exists a unique probability measure $\pi$ such that for any $\mathbf{w}^{0}$ :

$$
\left\|P^{t}\left(\mathbf{w}^{0}, \mathbf{X} ; \cdot\right)-\pi\right\| \rightarrow 0
$$

as $t \rightarrow \infty$.

When $\mathbf{X}^{t}$ is time dependent, the model may not have a stationary distribution.

However, as $t \rightarrow \infty$, the dependence on the initial state vanishes. When $\mathbf{X}^{t}=\mathbf{X}$ for all $t$, the model does have a stationary distribution, $\pi$.

The next corollary follows from Propositions 2, 3 and 4 and summarizes the economic significance of this section's results.

Corollary 1. Suppose that $\rho^{d}(i, j)<\infty$ iff $\rho^{s}(i, j)<\infty$ for all $i \neq j$ and that Assumptions 1. 2. 3 , 4 and 5 hold. Then,

$$
\left(w_{i}^{t} \perp w_{j}^{t}\right) \mid\left(\mathbf{X}^{t-1}\right)
$$

${ }^{10}$ This generalizes Calvó-Armengol \& Jackson 2004) (Proposition 1) and Calvó-Armengol \& Jackson (2007) (Theorem 1), where they present results for the stationary distribution of a homogeneous Markov chain. 
as $t \rightarrow \infty$ iff $i$ and $j$ are not socially connected. Moreover, as $t \rightarrow \infty, \mathbf{w}^{t} \mid\left(\mathbf{X}^{t-1}\right)$ becomes associated.

The assumption that $\rho^{d}(i, j)<\infty$ iff $\rho^{s}(i, j)<\infty$ reflects the fact that the social network has an influence on the dependence structure of the wage distribution (see Example 2). Since the dependence on the initial state vanishes as $t \rightarrow \infty$ (see Proposition 4), Propositions 2 and 3 hold irrespective of the initial state as $t \rightarrow \infty$.

This completes the analysis of the dependence structure of the model. In the next section, we study the comparative dynamics of the model.

\subsection{The Impacts of Shocks on Wage Dynamics}

In this section, we discuss the impact of changes in $\mathbf{X}^{t}$ on the distributions of wages. We assume the following:

Assumption 6. $\varphi(\mathbf{w}, \mathbf{X}, \varepsilon)$ is increasing in $\mathbf{X}$.

This implies that $\mathbf{X}$ has a positive impact (in the sense of FOSD; see Lemma 11) on the distribution of future wages. It implies the following:

Proposition 5. Suppose that Assumption 1 holds and let $\mathbf{X}^{t} \geq \tilde{\mathbf{X}}^{t}$. Then, $\mathbf{w}^{0} \succeq \tilde{\mathbf{w}}^{0}$ implies that $\mathbf{w}^{t}\left|\left(\mathbf{X}^{t-1}\right) \succeq \tilde{\mathbf{w}}^{t}\right|\left(\tilde{\mathbf{X}}^{t-1}\right)$ for all $t$.

Proposition 5 follows from standard results for the comparison of monotone stochastic processes (see the appendix for a proof and references). Note that under the conditions of Proposition 4 the dependence on the initial state vanishes as $t \rightarrow \infty$. Note also that Proposition 5 can be applied to Example 1 with $\mathrm{X}^{t}=\mathbf{x}$

Suppose that $\mathbf{X}^{t}$ represents individuals' levels of education. This implies that increasing the level of education of some individual $i$ will have a positive impact on the entire distribution of wages. Coupled with Corollary 1 it implies that the increase in $i$ 's level of education will have, for a sufficiently large $t$, a positive impact on any individual socially connected to $i$, and no impact on the rest of the population.

\footnotetext{
${ }^{11}$ Another example is the drop-out functions from Calvó-Armengol \& Jackson (2004) (Proposition 4) and Calvó-Armengol \& Jackson (2007) (Theorem 2).
} 
Note that in principle, Proposition 5 could be applied to changes in the network structure. Suppose that $\mathbf{G}^{s} \supseteq \tilde{\mathbf{G}}^{s}$ implies that $\varphi_{\mathbf{G}^{s}}(\mathbf{w}, \mathbf{X}, \boldsymbol{\varepsilon}) \geq \varphi_{\tilde{\mathbf{G}}^{s}}(\mathbf{w}, \mathbf{X}, \boldsymbol{\varepsilon})$. That is, adding links to the social network has a positive impact on the wage distribution at a given time. Then, Proposition 5 implies that this dominance holds for all $t$. Such an assumption may represent situations where the information transmitted through the network is non-rival. For example, individuals may gain information from their peers about how to access government programs or evade taxes (Bellemare et al. 2012). The key is that when information is non-rival, everyone benefits from an individual having more links.

However, if the information transmitted through the network is rival (for example, information about a particular job opening, as in Example 1), the addition of a link will usually be beneficial to some, but detrimental to others. In Example 1, individuals prefer to have many links since it increases the probability that they receive indirect job offers. However, they prefer to be linked (all else equal) to individuals with relatively few links, as it increases the probability that such an individual will transmit an (indirect) offer to them, and not to another peer. Increasing the number of links will therefore have ambiguous effects on the wage distribution.

This completes the analysis of the theoretical framework. In the next section, we present our empirical application.

\section{A Coherent Structural Econometric Model}

We now discuss our ability to estimate the model developed in the previous sections. Although there is nothing that conceptually prevents the estimation of models such as the one presented in Example 1, the availability of data prevents the identification of such models. One would have to observe the entire network structure, as well as the offers transmitted.

An alternative would be to use existing econometric models such as linear DSAR models (Baltagi et al. 2014), where:

$$
\ln \left(\mathbf{w}^{t+1}\right)=\mathbf{X} \boldsymbol{\beta}+\lambda \mathbf{G}^{s} \ln \left(\mathbf{w}^{t+1}\right)+\rho \ln \left(\mathbf{w}^{t}\right)+\varepsilon^{t+1}
$$


Note that this linear DSAR model is monotone, and that Assumption 3 holds 12 However, the linearity of the model has many unwanted features.

First, individuals' wages are negatively (and symmetrically) influenced by peers with lower wages (through $\lambda \mathbf{G}^{s} \ln \left(\mathbf{w}^{t+1}\right)$ ). This is incompatible with an interpretation of peer effects in terms of information transmission. Second, there is no well-defined unemployment level. Third, the model features too much variation in wages, compared to what is observed. In particular, the probability that an individual keeps the same wage for two consecutive periods is 0 if $\varepsilon$ is drawn from a continuous distribution. Finally, as in Example 1, it requires detailed knowledge of the social network and of the wage distribution for the entire population.

We therefore propose the following model, which does not have the unwanted features of the linear DSAR, but can be identified using available data.

\subsection{The Econometric Model}

We assume that every period is characterized by the following phases:

1. Each individual is laid off with probability $\delta \in(0,1)$.

2. Each individual receives a job offer with probability $\gamma \in(0,1)$. Let $\boldsymbol{\omega}\left(\mathbf{X}^{t}, \mathbf{w}^{t}\right)$ be the distribution of offers. Assume that it follows a lognormal distribution,

$$
\ln \omega_{i}^{t+1}=\mathbf{x}_{i}^{t} \boldsymbol{\beta}+\lambda \ln \left(w_{i}^{t}\right)+\tau E_{i}^{t}+\varepsilon_{i}^{t}
$$

where $E_{i}^{t}$ is the number of $i$ 's peers who are employed at time $t$, with $\lambda, \tau>0$ and $\varepsilon_{i}^{t}$ is normally distributed. We assume that:

(a) If the direct offer received is less than the individual's current wage, the individual keeps his current job

(b) If the direct offer received is larger than the individual's current wage, the individual accepts the job offer

\footnotetext{
${ }^{12}$ Also note that even if Assumption 5 does not hold, the linear DSAR is stationary, provided conditions on $\lambda$ are met.
} 
Note that, contrary to Example 1, the network effects are directly embedded in the distribution of offers, which allows for the identification and estimation of the model. Note that we can write $i$ 's wage at $t+1$ as follows:

$$
\begin{aligned}
\ln \left(w_{i}^{t+1}\right) & =\left(1-D_{\delta}\right) D_{\gamma} \max \left\{0,\left(\mathbf{x}_{i}^{t} \boldsymbol{\beta}+(\lambda-1) \ln \left(w_{i}^{t}\right)+\tau E_{i}^{t}+\varepsilon_{i}^{t}\right)\right\} \\
& +D_{\delta} D_{\gamma} \max \left\{0,\left(\mathbf{x}_{i}^{t} \boldsymbol{\beta}+\lambda \ln \left(w_{i}^{t}\right)-\ln (b)+\tau E_{i}^{t}+\varepsilon_{i}^{t}\right)\right\} \\
& +\left(1-D_{\delta}\right) \ln \left(w_{i}^{t}\right)+D_{\delta} \ln (b)
\end{aligned}
$$

where $D_{p}$ denotes the (Bernouilli distributed) random variable that takes a value of 1 with probability $p$, and 0 otherwise.

We obtain a dynamic nonlinear panel data model that we can estimate using actual data. Such a model needs some additional assumptions to deal with the initial condition issue. Specifically, we do not observe the initial state, but it is likely to be correlated with individuals' unobserved characteristics. To our knowledge, there is no transformation that controls for unobservable individual fixed effects in non-linear settings. We therefore use the estimation method proposed by Wooldridge (2005) and assume the following random effects model 13

$$
\varepsilon_{i}^{t}=\alpha_{i}+u_{i}^{t}
$$

where $u_{i}^{t} \sim \mathcal{N}\left(0, \sigma_{u}\right)$.

We then model the random effect as a function of the initial conditions. Specifically:

$$
\alpha_{i}=a_{1} \ln w_{i}^{0}+\eta_{i}
$$

where $\eta_{i} \sim \mathcal{N}\left(0, \sigma_{\eta}\right)$ and $w_{i}^{0}$ is $i$ 's initial wage.

To provide more flexibility in the specification of the conditional distribution of the unobserved effect, we allow $\alpha_{i}$ to be correlated with the exogenous regressors over all the periods. To this end, we use the Mundlak specification

\footnotetext{
$\sqrt[13]{\text { Arulampalam \& Stewart } \sqrt{2009)}}$ compare three parametric estimation methods to address initial condition issues in non-linear dynamic settings: the Heckman method, the Orme method and the Woolridge method. They do not find one to be clearly superior to the others.
} 
of correlated random effects (CRE) (Mundlak, 1978):

$$
\alpha_{i}=a_{1} \ln w_{i}^{0}+\boldsymbol{z}_{\boldsymbol{i}} \boldsymbol{\rho}+\eta_{i}
$$

where $\boldsymbol{z}_{i}=\left(\bar{x}_{i 1}, \ldots, \bar{x}_{i K}, \ln w_{i}^{0} \times \bar{x}_{i 1}, \ldots, \ln w_{i}^{0} \times \bar{x}_{i K}\right)$ is a vector of the means of the exogenous regressors over all the periods and their interaction with the initial state.

Then, we can write the contribution of the likelihood of observing $w_{i}^{t+1}$ conditional on $w_{i}^{t}, E_{i}^{t}, w_{i}^{0}$, on the exogenous regressors $\boldsymbol{x}_{\boldsymbol{i}}^{\boldsymbol{t}}$ and $\boldsymbol{z}_{\boldsymbol{i}}$, on the unobserved heterogeneity $\eta_{i}$ and on all the parameters of the model. Using Equation 2 , we define five probabilities: the probability that the individual receives an offer between $t$ and $t+1$ that is superior to his wage in $t\left(w_{i}^{t+1}>w_{i}^{t}\right)$, the probability that the individual is both working at $t$ and $t+1$ at the same wage rate $\left(w_{i}^{t+1}=w_{i}^{t} \mid w_{i}^{t}>b\right)$, the probability that the individual is unemployed both in $t$ and in $t+1$ and earns social welfare $w_{i}^{t+1}=w_{i}^{t} \mid w_{i}^{t}=b$, the probability that the individual has lost his job at $t$ but simultaneously receives a job offer for $t+1$ that is inferior to his wage in $t$ but still superior to the social welfare $b$ and that he accepts $\left(w_{i}^{t+1}<w_{i}^{t} \mid w_{i}^{t+1}>b\right)$, and finally the probability that the individual loses his job without finding a new one between $t$ and $t+1\left(w_{i}^{t+1}=b \mid w_{i}^{t}>b\right)$. Then, the conditional contribution of individual $i$ to the likelihood at time $t+1$ 
can be written as:

$$
\begin{aligned}
L_{i}^{t+1}= & L\left(w_{i}^{t+1} \mid w_{i}^{t}, E_{i}^{t}, w_{i}^{0}, \eta_{i}, \boldsymbol{x}_{\boldsymbol{i}}^{\boldsymbol{t}}, \boldsymbol{z}_{\boldsymbol{i}}, \theta\right) \\
= & {\left[\frac{\gamma}{\sigma_{u}} \phi\left(\frac{\ln \left(w_{i}^{t+1}\right)-\left(\boldsymbol{x}_{\boldsymbol{i}}^{\boldsymbol{t}} \boldsymbol{\beta}+\lambda \ln \left(w_{i}^{t}\right)+\tau E_{i}^{t}+a_{1} \ln w_{i}^{0}+\boldsymbol{z}_{\boldsymbol{i}} \boldsymbol{\rho}+\eta_{i}\right)}{\sigma_{u}}\right)\right]^{\mathbb{1}\left\{w_{i}^{t+1}>w_{i}^{t}\right\}} } \\
\times & {\left[(1-\delta)(1-\gamma)+(1-\delta) \gamma \Phi\left(-\frac{\boldsymbol{x}_{\boldsymbol{i}}^{\boldsymbol{t}} \boldsymbol{\beta}+(\lambda-1) \ln \left(w_{i}^{t}\right)+\tau E_{i}^{t}+a_{1} \ln w_{i}^{0}+\boldsymbol{z}_{\boldsymbol{i}} \boldsymbol{\rho}+\eta_{i}}{\sigma_{u}}\right)\right]^{\mathbb{1}\left\{w_{i}^{t+1}=w_{i}^{t} \mid w_{i}^{t}>b\right\}} } \\
\times & {\left[(1-\gamma)+\gamma \Phi\left(-\frac{\boldsymbol{x}_{\boldsymbol{i}}^{\boldsymbol{\beta}} \boldsymbol{\beta}+(\lambda-1) \ln \left(w_{i}^{t}\right)+\tau E_{i}^{t}+a_{1} \ln w_{i}^{0}+\boldsymbol{z}_{\boldsymbol{i}} \boldsymbol{\rho}+\eta_{i}}{\sigma_{u}}\right)\right]^{\mathbb{1}\left\{w_{i}^{t+1}=w_{i}^{t} \mid w_{i}^{t}=b\right\}} } \\
\times & {\left[\frac{\delta \gamma}{\sigma_{u}} \phi\left(\frac{\ln \left(w_{i}^{t+1}\right)-\left(\boldsymbol{x}_{\boldsymbol{i}}^{\boldsymbol{t}} \boldsymbol{\beta}+\lambda \ln \left(w_{i}^{t}\right)+\tau E_{i}^{t}+a_{1} \ln w_{i}^{0}+\boldsymbol{z}_{\boldsymbol{i}} \boldsymbol{\rho}+\eta_{i}\right)}{\sigma_{u}}\right)\right]^{\mathbb{1}\left\{w_{i}^{t+1}<w_{i}^{t} \mid w_{i}^{t+1}>b\right\}} } \\
\times & {\left[\delta(1-\gamma)+\delta \gamma \Phi\left(-\frac{\boldsymbol{x}_{\boldsymbol{i}}^{\boldsymbol{t}} \boldsymbol{\beta}+\lambda \ln \left(w_{i}^{t}\right)-\ln (b)+\tau E_{i}^{t}+a_{1} \ln w_{i}^{0}+\boldsymbol{z}_{\boldsymbol{i}} \boldsymbol{\rho}+\eta_{i}}{\sigma_{u}}\right)\right]^{\mathbb{1}\left\{w_{i}^{t+1}=b \mid w_{i}^{t}>b\right\}} }
\end{aligned}
$$

with $\phi$ and $\Phi$ denoting, respectively, the probability and cumulative density functions of the standard normal distribution.

Then, we integrate out $\eta_{i}$ to obtain the conditional contribution of individual $i$ to the likelihood of the model that is the density of $\left(w_{i}^{1}, w_{i}^{2}, \ldots, w_{i}^{T}\right)$ given $\left(w_{i}^{0}, \boldsymbol{x}_{\boldsymbol{i}}, \boldsymbol{z}_{\boldsymbol{i}}, E_{i}, \theta\right)$ :

$L\left(\left(w_{i}^{1}, w_{i}^{2}, \ldots, w_{i}^{T}\right) \mid w_{i}^{0}, \boldsymbol{x}_{\boldsymbol{i}}, \boldsymbol{z}_{\boldsymbol{i}}, E_{i}, \theta\right)=\int\left(\prod_{t=1}^{T} L\left(w_{i}^{t} \mid w_{i}^{t-1}, E_{i}^{t-1}, w_{i}^{0}, \eta_{i}, \boldsymbol{x}_{\boldsymbol{i}}, \boldsymbol{z}_{\boldsymbol{i}}, \theta\right)\right) \frac{1}{\sigma_{\eta}} \phi\left(\eta_{i}\right) d \eta$

where the integral will be computed using the Gaussian-Hermite quadrature.

Then, we sum the log transformation of each contribution over all individuals to obtain the log-likelihood of the model:

$$
L=\sum_{i=1}^{N} \ln \left[\int\left(\prod_{t=1}^{T} L\left(w_{i}^{t} \mid w_{i}^{t-1}, E_{i}^{t-1}, w_{i}^{0}, \eta_{i}, \boldsymbol{x}_{\boldsymbol{i}}, \boldsymbol{z}_{\boldsymbol{i}}, \theta\right)\right) \frac{1}{\sigma_{\eta}} \phi\left(\eta_{i}\right) d \eta\right]
$$

One could argue that the random effect corrects for the endogeneity of $w_{i}^{t-1}$, but not for the possible endogeneity of the number of employed peers, $E_{i}^{t-1}$. As a robustness check, we estimate a joint model for the wage dynamics and 
the number of employed friends where we permit correlated random effects on two endogenous variables (an individual's number of employed peers and his previous wage) ${ }^{14}$ That is, we add to the previous estimation an ordered probit model of the number of employed peers:

$$
\begin{aligned}
\ln \left(w_{i}^{t+1}\right) & =f_{w}\left(w_{i}^{t}, E_{i}^{t}, w_{i}^{0}, \boldsymbol{x}_{\boldsymbol{i}}^{t}, \boldsymbol{z}_{\boldsymbol{i}}, \eta_{i}, \theta, u_{i}^{t}\right) \\
E_{i}^{t+1} & =0 \text { if } e_{0} w_{i}^{t}+e_{1} E_{i}^{t}+\boldsymbol{x}_{\mathbf{2}}^{t} \boldsymbol{e}+\nu_{i}+u_{2 i}^{t}<a_{0} \\
& =1 \text { if } a_{0} \leq e_{0} w_{i}^{t}+e_{1} E_{i}^{t}+\boldsymbol{x}_{\mathbf{2}}^{t} \boldsymbol{e}+\nu_{i}+u_{2 i}^{t}<a_{1} \\
& =2 \text { if } a_{1} \leq e_{0} w_{i}^{t}+e_{1} E_{i}^{t}+\boldsymbol{x}_{\mathbf{2}}^{t} \boldsymbol{e}+\nu_{i}+u_{2 i}^{t}<a_{2} \\
& =3 \text { if } a_{2} \leq e_{0} w_{i}^{t}+e_{1} E_{i}^{t}+\boldsymbol{x}_{\mathbf{2}}^{t} \boldsymbol{e}+\nu_{i}+u_{2 i}^{t}
\end{aligned}
$$

where the random effects $\nu_{i}$ and $\eta_{i}$ are jointly normally distributed with variances $\sigma_{\nu}$ and $\sigma_{\eta}$, and correlation $\rho$. The errors $\left(u_{i}^{t}, u_{2 i}^{t}\right)$ are assumed to be independent and normally distributed, with variances $\sigma_{u}$ to be estimated and $\sigma_{u_{2}}$ fixed at 1 .

Note that this model is compatible with the framework developed in Section 2:

Proposition 6. The econometric model respects Assumptions 1 to 5, and such that $\mathbf{G}^{d}=\mathbf{G}^{s}$.

A proof is provided in the appendix. In particular, note that the conditions of Proposition 5 hold so that any change in the parameters driving the distribution of offers (i.e. $\boldsymbol{\beta}, \lambda$ and $\tau$ ) does not only have an impact on the expected wage, but on the entire distribution of future wages ${ }^{15}$

We now briefly present the data.

\subsection{Data}

We use the BHPS, covering the period 1991-2008, to examine the wage dynamics of British men and women. This panel is a nationally representative

\footnotetext{
${ }^{14}$ Stewart $(2007)$ also estimates a joint bivariate probit model with correlated error terms and random effects.

${ }^{15}$ See the proof of Proposition 6 in the appendix for details with respect to FOSD.
} 
sample of households whose members are re-interviewed each year.

The sample is restricted to 18- to 65-year-olds who are in the labour force during the whole period (we thus exclude retired individuals, full-time students and individuals in family care). We drop all observations with missing information on usual gross pay per month and the number of hours normally worked per week. We trim the top and bottom $1 \%$ tails of wages and working hours, and we compute the hourly wage by dividing the usual gross pay per month by the number of hours normally worked per month. Finally, wages are deflated by the consumer price index and computed in 2008 British pounds. We also observe the year in which individuals begin their current job. We use that information to identify changes in wages between two periods that come from a job offer or termination, and not from measurement errors or salary raises.

For all individuals, we observe their education level, age, marital status and the employment status of their three best friends. The survey also collects information on individuals' health status, which we use as a dummy variable indicating whether the health of an individual limits the type or amount of work he could perform. Finally, we add the regional unemployment rate for each period to the panel ${ }^{16}$ As information on friends is only collected in evennumbered years, we restrict our sample to those years $(1992,1994, \ldots, 2006$, 2008) so that we consider nine periods of two years.

We keep observations for individuals who provide information on at least one friend each year; we obtain a balanced panel of 956 individuals (8,604 observations). Descriptive statistics are presented in Tables 1 and 2 .

\subsection{Results}

Estimates of the parameters are presented in Table 3 . We compare three models: one with uncorrelated random effects where initial conditions are assumed to be exogenous, a second with uncorrelated random effects where we

\footnotetext{
${ }^{16}$ Twelve regions are reported: North East, North West, Yorkshire and the Humber, East Midlands, West Midlands, East of England, London, South East, South West, Wales, Scotland and Northern Ireland.
} 
include a dependency to the initial wage, and a third with correlated random effects and a dependency to the initial conditions ${ }^{17}$

We find a job destruction rate $(\delta)$ of $15 \%$ and a rate of offers $(\gamma)$ of $65 \%$. The probability of being unemployed in a given period is then approximately $5.2 \%(0.15 \times(1-0.65))$, which is slightly lower then the unemployment rate in the UK during this time period 18 Also note that the rate of offers represents any offers, and not necessarily offers that are accepted, which accounts for the relatively high rate.

We find a significant dependency on the initial conditions, implying that the wage dependence persists over 16 years. This is reflected by the fact that the impact on an individual's wage at time $t$ has a large and statistically significant impact on the distribution of new offers at time $t+1$.

When we take random effects into account, and then allow for correlated random effects, the effect of the current wage on the distribution of offers decreases slightly. However, we still find a small but positive and significant effect of the current wage on the average distribution of job offers. A $10 \%$ increase in the current wage increases the average wage of an individual's job offers by by $0.8 \%$. There is a significant impact of the number of employed friends in the third model (column 3 of Table 3). Having an additional employed friend increases the average wage of an individual's job offers by by $2.8 \%$. Not surprisingly, a high unemployment rate, poor health conditions, being single, having minimal education and being female all have a negative effect on the distribution of job offers.

We further compare the results with those obtained when we estimate the model for women only. Wage dynamics are very gender dependent, so separate estimations may be more relevant. Furthermore, we observe greater variability for women than for men with respect to the number of employed friends an

\footnotetext{
${ }^{17}$ Correlated random effects are computed by including the means of the exogenous variables over the periods and their interactions with the initial wage.

${ }^{18} \mathrm{~A}$ precise calculation of the probability of being unemployed would include the probability that an individual receives an offer that they refuse.
} 
individual has ${ }^{19}$ Results are displayed in Table 4 . In the two first columns, we present the results for individuals who give information on each of their three best friends (for women in the first column and for all individuals in the second column). Estimates are very close to the previous results but show a stronger effect of the network on women's wages. For women, having one more employed friend increases the average offer by $4 \%$ instead of $2.8 \%$ for all individuals.

In the last two columns, we add individuals who provide information on only one or two friends. The network effect stays positive and significant for women, whereas it almost disappears when we include men. Whereas gender differences in the density and composition of social networks have been studied in the literature (Ioannides \& Loury, 2004), it would also be interesting to understand gender differences in the use and the efficiency of social contacts for improving labour-market outcomes.

Finally, we estimate a joint model for wage dynamics and for the number of friends employed. Results are presented in Table 5. The estimation is for women only ${ }^{20}$ We find a stronger effect of the network. Other coefficients are remarkably stable. Our estimation of the correlation between the two random effects is not statistically significant.

We conclude by discussing areas for further research.

\section{Conclusion}

The empirical literature on the effects of personal networks in the labour market is small but expanding. We contribute to that literature by proposing a non-linear DSAR and estimating the impact of the employment status of an individual's three best friends on the distribution of his job offers. Our structural econometric model is based on our general microeconomic framework,

\footnotetext{
${ }^{19}$ More than $65 \%$ of employed men have their three best friends employed, compared with $45 \%$ for employed women.

${ }^{20}$ The results are qualitatively the same for the whole sample. Results are available upon request.
} 
which allows for a large variety of econometric specifications. We discuss some examples below.

We find that the number of employed friends has a positive effect on the distribution of job offers. This finding is important, as it introduces dependence between individuals' wages. It also suggests that information about the status of an individual's peers can be as relevant as the information about the peers themselves.

An interesting finding is that the employment status of an individual's peers has a larger effect on the distribution of job offers for women than for men. This suggests that certain groups of individuals (in this case, women) can be more affected by negative shocks on their peers. Determining which groups are more or less exposed to the status of their peers is a promising area of research.

Another potential area for future research (which may be constrained by a lack of available data) is to study the spread of negative aggregate shocks. Our general framework allows for the study of wage dynamics outside the stationary distribution. The fact that wages are positively correlated points to a multiplicative effect of recessions: the total impact is a combination of both the direct impact of a shock, as well as the indirect impact that occurs through the employment status of individuals' peers.

Throughout the paper, we assume that the social network structure is fixed and independent of wage dynamics. This is consistent with our empirical application, since wages are unlikely to be a significant determinant of close friendships. However, some networks (e.g. co-workers) are much more likely to be determined as a function of labour-market outcomes. This raises interesting and challenging questions as to the extent to which individuals are strategic in choosing their friends in time-varying endogenous social networks. 


\section{References}

Arulampalam, W., \& Stewart, M. B. (2009). Simplified implementation of the heckman estimator of the dynamic probit model and a comparison with alternative estimators. Oxford bulletin of economics and statistics, 71(5), $659-681$.

Åslund, O., Hensvik, L., \& Skans, O. N. (2014). Seeking similarity: How immigrants and natives manage in the labor market. Journal of Labor Economics, 32(3), 405-441.

Baltagi, B. H., Fingleton, B., \& Pirotte, A. (2014). Estimating and forecasting with a dynamic spatial panel data model*. Oxford Bulletin of Economics and Statistics, 76(1), 112-138.

Bayer, P., Topa, G., \& Ross, S. L. (2009). Place of work and place of residence: Informal hiring networks and labor market. Journal of Political Economy, $116,1150-1196$.

Bellemare, C., Fortin, B., Joubert, N., \& Marchand, S. (2012). Effets de pairs et fraude sociale: une analyse économétrique sur données françaises. Tech. rep., CIRANO.

Cahuc, P., \& Fontaine, F. (2009). On the efficiency of job search with social networks. Journal of Public Economic Theory, 11(3), 411-439.

Calvó-Armengol, A. (2004). Job contact networks. Journal of economic Theory, $115(1), 191-206$.

Calvó-Armengol, A., \& Jackson, M. O. (2004). The effects of social networks on employment and inequality. American economic review, (pp. 426-454).

Calvó-Armengol, A., \& Jackson, M. O. (2007). Networks in labor markets: Wage and employment dynamics and inequality. Journal of economic theory, 132(1), 27-46. 
Calvó-Armengol, A., \& Zenou, Y. (2005). Job matching, social network and word-of-mouth communication. Journal of urban economics, 57(3), 500-522.

Campbell, K. E. (1988). Gender differences in job-related networks. Work and occupations, 15(2), 179-200.

Cappellari, L., \& Tatsiramos, K. (2011). Friends' networks and job finding rates. Tech. rep., ISER Working Paper Series.

Cingano, F., \& Rosolia, A. (2012). People i know: job search and social networks. Journal of Labor Economics, 30(2), 291-332.

Dieye, R., \& Fortin, B. (2014). Peer effects heterogeneity: Theory and application.

Dorea, C., \& Pereira, A. (2006). A note on a variation of doeblin's condition for uniform ergodicity of markov chains. Acta Mathematica Hungarica, 110(4), $287-292$.

Dustmann, C., Glitz, A., \& Schönberg, U. (2011). Referral-based job search networks. IZA discussion paper.

Fontaine, F. (2008). Why are similar workers paid differently? the role of social networks. Journal of Economic Dynamics and Control, 32(12), 3960-3977.

Galeotti, A., \& Merlino, L. P. (2014). Endogenous job contact networks. International economic review, 55(4), 1201-1226.

Granovetter, M. (1983). The strength of weak ties: A network theory revisited. Sociological theory, 1(1), 201-233.

Granovetter, M. S. (1973). The strength of weak ties. American journal of sociology, (pp. 1360-1380).

Hanson, S., \& Pratt, G. (1991). Job search and the occupational segregation of women. Annals of the Association of American Geographers, 81(2), 229-253. 
Ibarra, H. (1992). Homophily and differential returns: Sex differences in network structure and access in an advertising firm. Administrative science quarterly, (pp. 422-447).

Ioannides, Y. M., \& Loury, L. D. (2004). Job information networks, neighborhood effects, and inequality. Journal of economic literature, (pp. 1056-1093).

Ioannides, Y. M., \& Soetevent, A. R. (2006). Wages and employment in a random social network with arbitrary degree distribution. The American economic review, (pp. 270-274).

Koller, D., \& Friedman, N. (2009). Probabilistic graphical models: principles and techniques. MIT press.

Kramarz, F., \& Skans, O. N. (2014). When strong ties are strong: Networks and youth labour market entry. The Review of Economic Studies, 81(3), 1164-1200.

Marmaros, D., \& Sacerdote, B. (2002). Peer and social networks in job search. European economic review, 46(4), 870-879.

Montgomery, J. D. (1991). Social networks and labor-market outcomes: Toward an economic analysis. The American economic review, (pp. 1408-1418).

Montgomery, J. D. (1992). Job search and network composition: Implications of the strength-of-weak-ties hypothesis. American Sociological Review, (pp. $586-596)$.

Müller, A., \& Stoyan, D. (2002). Comparison methods for stochastic models and risks. 2002. John Wiley\&SSons Ltd., Chichester.

Neumark, D., \& Postlewaite, A. (1998). Relative income concerns and the rise in married women's employment. Journal of public Economics, 70(1), 157-183.

Pellizzari, M. (2010). Do friends and relatives really help in getting a good job? Industrial \&5 Labor Relations Review, 63(3), 494-510. 
Rees, A. (1966). Information networks in labor markets. The American Economic Review, (pp. 559-566).

Stewart, M. B. (2007). The interrelated dynamics of unemployment and lowwage employment. Journal of applied econometrics, 22(3), 511-531.

Wooldridge, J. M. (2005). Simple solutions to the initial conditions problem in dynamic, nonlinear panel data models with unobserved heterogeneity. Journal of applied econometrics, 20(1), 39-54. 


\section{Appendix}

\subsection{Proofs}

Proof (of Lemma 1). See Müller \& Stoyan (2002), theorem 5.2.3.

Proof (of the Discussion in Example 2). From Lemma 1, it is sufficient to show that $\mathbf{w}^{t} \geq \hat{\mathbf{w}}^{t}$ implies that $\mathbf{w}^{t+1} \succeq \hat{\mathbf{w}}^{t+1}$. The direct offers are given by:

$$
\omega_{i}^{t}=D_{\gamma}\left(\alpha w_{i}^{t}+(1-\alpha) x_{i}\right) \exp \left\{\varepsilon_{i}^{t}\right\}+b
$$

where $\varepsilon_{i}^{t}$ is independent and identically distributed from $N\left(0, \sigma^{2}\right)$ and $D_{\gamma}$ is a Bernoulli distributed random variable that takes a value of 1 with probability $\gamma$. Note that $\mathbf{w}^{t} \geq \hat{\mathbf{w}}^{t}$ implies that $\boldsymbol{\omega}^{t} \succeq \hat{\boldsymbol{\omega}}^{t}$ (see Müller \& Stoyan (2002), theorems 3.3.10, 3.3.11 and 3.3.13). We can define the following:

$$
r_{i}=\max \left\{D_{\delta} b+\left(\mathbf{1}-D_{\delta}\right) w_{i}^{t}, \omega_{i}^{t}\right\}
$$

and

$$
s_{i}=\min \left\{D_{\delta} b+\left(\mathbf{1}-D_{\delta}\right) w_{i}^{t}, \omega_{i}^{t}\right\}
$$

where $D_{\delta}$ is a Bernoulli distributed random variable that takes value 1 with probability $\delta$. Therefore, $\mathbf{w}^{t} \geq \hat{\mathbf{w}}^{t}$ implies that $\mathbf{r} \succeq \hat{\mathbf{r}}$ and $\mathbf{s} \succeq \hat{\mathbf{s}}$ (see Müller \& Stoyan (2002), theorem 3.3.10). Finally, we have that

$$
\mathbf{w}^{t+1}=\max \left\{\boldsymbol{r}, s_{1} \mathbf{d}_{1}, \ldots, s_{n} \mathbf{d}_{n}\right\}
$$

so, (again from Müller \& Stoyan (2002), theorem 3.3.10), we have that $\mathbf{w}^{t} \geq \hat{\mathbf{w}}^{t}$ implies that $\mathbf{w}^{t+1} \succeq \hat{\mathbf{w}}^{t+1}$. QED

Proof (of Proposition 2). See Müller \& Stoyan (2002), theorem 3.10.7 and theorem 4.3.13.

Proof (of Proposition 3). The proof is based on the theory of independencies for Markov network models. The reference used here is Koller \& Friedman (2009), section 4.3 .

Let us consider the set of all wages, for all individuals, at any point in time from $t=0$ to $t=T$, conditional on the characteristics $\mathbf{X}^{t}$, i.e. $\left\{w_{1}^{t}, \ldots, w_{n}^{T} \mid\left(\mathbf{X}^{T-1}\right)\right\}$.

We now define a Markov network structure. Let $\mathcal{H}$ be an undirected graph where a typical node is $(i, t)$ for $i \in N$ and $0 \leq t \leq T$. Consider $(i, t)$ and $(j, \tau)$ in $\mathcal{H}$. We set $\tau \geq t$ without a loss of generality. We assume that a link exists between $(i, t)$ and $(j, \tau)$ if one of the following conditions holds:

1. $i=j$ and $\tau=t-1$

2. $j \in N^{d}(i)$ and $\tau=t-1$

3. $j \in N^{d}(i)$ and $\tau=t$

We provide an example in Figure 2 


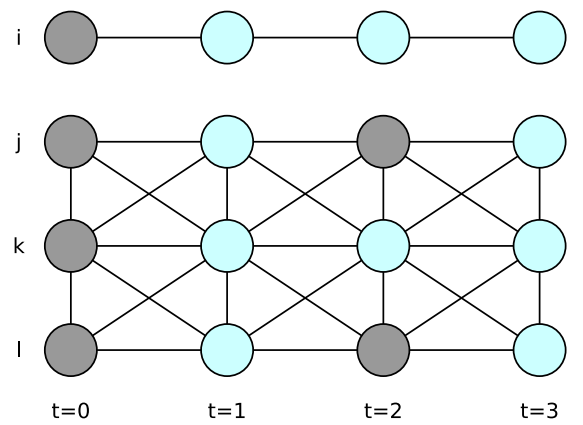

Given an arbitrary graph $\mathcal{G}$ on $(i, t)$, the Markov blanket of a generic random variable $\mathbf{Z}=\left\{z_{i}^{t}\right\}$ is defined as:

$$
I(\mathcal{G})=\left\{\left(z_{i}^{t} \perp \mathbf{Z}-\left\{z_{j}^{\tau}\right\}_{(j, \tau),(i, t) \in \mathcal{G}}-z_{i}^{t}\right) \mid\left\{z_{j}^{\tau}\right\}_{(j, \tau),(i, t) \in \mathcal{G}}\right\}
$$

Conditional on the neighbours of $(i, t)$ in $\mathcal{G}$, the realizations on $z_{i}^{t}$ are independent of the other variables in $\mathbf{Z}$.

In the context of $\left\{w_{1}^{t}, \ldots, w_{n}^{T} \mid\left(\mathbf{X}^{T-1}\right)\right\}$ and $\mathcal{H}$, Assumption 4 implies that $\mathcal{H}$ summarizes the dependence structure of $z_{i}^{t} \equiv w_{i}^{t} \mid\left(\mathbf{X}^{t-1}\right)$. Since Assumption 3 holds, looking at the Markov blanket is sufficient to describe the dependence structure (see Koller \& Friedman (2009), corollary 4.1).

For instance, in the example in Figure 2, we see that $w_{i}^{1}$ and $w_{l}^{1}$ are independent, conditional on $\mathbf{w}^{0},\left(\mathbf{X}^{0}\right)$ (i.e. there is no path between $(i, 1)$ and $(j, 1))$. However, there are paths between, say, $(j, 2)$ and $(l, 2)$. More importantly, there is at least one path between $(j, 2)$ and $(l, 2)$ that does not pass through $[(i, 0),(j, 0),(k, 0),(l, 0)]$ : the path through $(k, 1)$, as shown in Figure 3 .

Figure 3: Separation for $\left(\mathbf{w}^{0}, w_{j}^{2}, w_{l}^{2}\right)$

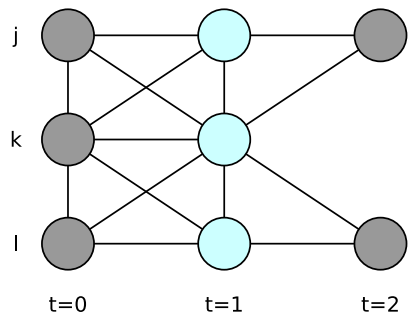


Then, $w_{j}^{2} \mid\left(\mathbf{X}^{1}\right)$ and $w_{l}^{2} \mid\left(\mathbf{X}^{1}\right)$ are dependent, conditional on $\mathbf{w}^{0}$. This follows formally from the definition of the dependence network, which implies that $\mathcal{H}$ is the minimal $I-$ map (see Koller \& Friedman (2009), theorem 4.6).

The same argument applies in general: $\mathbf{w}^{0}$ separates $w_{i}^{t} \mid\left(\mathbf{X}^{t-1}\right)$ and $w_{j}^{t} \mid\left(\mathbf{X}^{t-1}\right)$ if and only if the shortest path between $i$ and $j$ in the dependence network is greater than $t$, i.e. iff $\rho^{d}(i, j)>t$. QED

Proof (of Proposition 4). The proof is based on Dorea \& Pereira (2006). From Theorems 2 and 3, it is sufficient to show that there exists a probability $\mu_{t}$, an integer $m_{t} \geq 1$, and constants $\alpha_{t}<1 / 2$ and $\beta_{t}>0$ such that for any $A \in \mathcal{B}^{n}, \mu_{t}(A)>\alpha_{t}$ implies that

$$
\inf _{\mathbf{w} \in W} P^{m_{t}}\left(\mathbf{w}^{0},\left(\mathbf{X}^{m_{t}-1}\right), A\right) \geq \beta_{t}
$$

We have:

$$
\begin{aligned}
P^{m_{t}}\left(\mathbf{w}^{0},\left(\mathbf{X}^{m_{t}-1}\right), A\right) & =\int_{W} P\left(\mathbf{w}, \mathbf{X}^{m_{t}-1}, A\right) P^{m_{t}-1}\left(\mathbf{w}^{0},\left(\mathbf{X}^{m_{t}-2}\right), d \mathbf{w}\right) \\
& \geq P\left(\mathbf{b}, \mathbf{X}^{m_{t}-1}, A\right) P^{m_{t}-1}\left(\mathbf{w}^{0},\left(\mathbf{X}^{m_{t}-2}\right), \mathbf{b}\right) \\
& \geq P\left(\mathbf{b}, \mathbf{X}^{m_{t}-1}, A\right) \underline{\delta}
\end{aligned}
$$

where the last inequality follows from Assumption 5 Letting $\mu_{t}(A)=P\left(\mathbf{b}, \mathbf{X}^{m_{t}-1}, A\right)$ completes the proof. QED

Proof (of Proposition 5). The proof follows directly from the successive application of theorem 4.3.8 from Müller \& Stoyan (2002).

Proof (of Proposition 6).

Monotone Process:

First, note that $\boldsymbol{\omega}$ is monotone (see Müller \& Stoyan (2002), theorems 3.3.10, 3.3.11 and 3.3.13). For any $i \in N$, we have

$$
w_{i}^{t+1}=\max \left\{D_{\delta} b+\left(\mathbf{1}-D_{\delta}\right) w_{i}^{t}, D_{\gamma} \omega_{i}^{t}\right\} .
$$

Then, $\phi$ is $\succeq$-monotone from Müller \& Stoyan (2002), theorem 3.3.10.

Association: This follows directly from the specification of $\varepsilon_{i}^{t}$.

Positive Distribution and Layoff Probability:

Every individual has a positive probability of being laid off, as well as receiving a job offer, and the distribution of offers has full support on $W$. This implies that Assumptions 3 and 5 hold.

Dependence Network: Assumption 4 holds for $\mathbf{G}^{d}=\mathbf{G}^{s}$. QED

\subsection{Tables}


Table 1: Summary statistics

\begin{tabular}{lcc}
\hline \hline \multicolumn{1}{c}{ Variable } & Mean $^{* *}$ & Std. Dev. \\
\hline All (N=956) & & \\
Age & 40.956 & 9.374 \\
Education level* $^{*}$ & 3.528 & 1.617 \\
Single & 0.227 & 0.419 \\
Health status & 0.084 & 0.278 \\
Employment & 0.938 & 0.241 \\
Hourly wage & 11.571 & 6.059 \\
Log of hourly wage & 2.185 & 0.736 \\
Regional unemployment rate & 6.69 & 2.267 \\
\hline Women (N=444) & & \\
Age & 41.265 & 9.182 \\
Education level & 3.396 & 1.588 \\
Single & 0.234 & 0.424 \\
Health status & 0.08 & 0.271 \\
Employment & 0.957 & 0.203 \\
Hourly wage & 10.069 & 5.261 \\
Log of hourly wage & 2.098 & 0.649 \\
Regional unemployment rate & 6.728 & 2.274 \\
\hline${ }^{*}$ Education is coded in seven levels. & \\
${ }^{* *}$ Mean over the nine periods (1992-2008). & \\
& &
\end{tabular}

Table 2: Summary statistics for the number of declared friends

\begin{tabular}{lcccc} 
Number of friends & 0 & 1 & 2 & 3 \\
\hline \hline All & & $2.1 \%$ & $5.6 \%$ & $92.3 \%$ \\
Female & & $1.3 \%$ & $5.0 \%$ & $93.7 \%$ \\
\hline & & & & \\
Number of employed friends & 0 & 1 & 2 & 3 \\
\hline \hline All & $2.7 \%$ & $12.2 \%$ & $31.8 \%$ & $53.3 \%$ \\
Female & $2.6 \%$ & $13.6 \%$ & $39.0 \%$ & $44.9 \%$ \\
\hline
\end{tabular}




\begin{tabular}{|c|c|c|c|}
\hline $\ln w_{i}^{t}$ & $\begin{array}{c}\text { Table 3: E } \\
\text { RE }\end{array}$ & $\begin{array}{l}\text { timates } \\
\text { RE with IC } \\
\text { Equi-correlation }\end{array}$ & $\begin{array}{c}\text { RE with IC } \\
\text { CRE }\end{array}$ \\
\hline \multirow[t]{2}{*}{$\ln w_{i}^{t-1}$} & 0.127 & 0.107 & 0.084 \\
\hline & $(0.016)$ & $(0.013)$ & $(0.018)$ \\
\hline \multirow{2}{*}{$E_{i}^{t-1}$} & 0.013 & 0.013 & 0.028 \\
\hline & $(0.011)$ & $(0.013)$ & $(0.013)$ \\
\hline \multirow[t]{2}{*}{ Age } & 0.0002 & 0.0006 & 0.025 \\
\hline & $(0.002)$ & (0.002) & (0.002) \\
\hline \multirow[t]{2}{*}{$\mathrm{Age}^{2}$} & -0.00004 & -0.00003 & -0.0004 \\
\hline & $(0.00005)$ & (0.00002) & $(0.00003)$ \\
\hline \multirow[t]{2}{*}{ Female } & -0.20 & -0.144 & -0.111 \\
\hline & $(0.01)$ & $(0.027)$ & $(0.046)$ \\
\hline \multirow[t]{2}{*}{ Education } & 0.095 & 0.087 & 0.100 \\
\hline & $(0.008)$ & (0.009) & $(0.011)$ \\
\hline \multirow[t]{2}{*}{ Single } & -0.004 & -0.0004 & -0.057 \\
\hline & (0.02) & $(0.028)$ & (0.032) \\
\hline \multirow[t]{2}{*}{ Health status } & -0.05 & -0.0050 & -0.057 \\
\hline & $(0.04)$ & $(0.04)$ & $(0.048)$ \\
\hline \multirow[t]{2}{*}{ Local unemployment rate } & -0.057 & -0.063 & -0.050 \\
\hline & $(0.005)$ & $(0.006)$ & $(0.005)$ \\
\hline \multirow[t]{2}{*}{$\ln w_{i}^{0}$} & & 0.148 & -0.140 \\
\hline & & $(0.016)$ & $(0.086)$ \\
\hline \multirow[t]{2}{*}{$\overline{\text { Single }}$} & & & -0.030 \\
\hline & & & $(0.114)$ \\
\hline \multirow[t]{2}{*}{$\overline{\text { Health status }}$} & & & -1.96 \\
\hline & & & $(0.156)$ \\
\hline \multirow[t]{2}{*}{$\overline{\text { Unemployment rate }}$} & & & -0.059 \\
\hline & & & (0.029) \\
\hline \multirow[t]{2}{*}{$\ln w_{i}^{0} \times \overline{\text { Single }}$} & & & 0.075 \\
\hline & & & $(0.049)$ \\
\hline \multirow[t]{2}{*}{$\ln w_{i}^{0} \times \overline{\text { Health status }}$} & & & 0.964 \\
\hline & & & $(0.074)$ \\
\hline \multirow{2}{*}{$\ln w_{i}^{0} \times \overline{\text { Unemployment rate }}$} & & & 0.041 \\
\hline & & & $(0.014)$ \\
\hline \multirow{2}{*}{ Constant } & 1.96 & 1.71 & 1.671 \\
\hline & $(0.10)$ & $(0.087)$ & (0.212) \\
\hline \multirow[t]{2}{*}{$\delta$} & 0.147 & 0.147 & 0.147 \\
\hline & $(0.006)$ & $(0.006)$ & $(0.006)$ \\
\hline \multirow[t]{2}{*}{$\gamma$} & 0.638 & 0.643 & 0.682 \\
\hline & $(0.014)$ & $(0.014)$ & $(0.016)$ \\
\hline \multirow[t]{2}{*}{$\sigma_{u}$} & 0.32 & 0.32 & 0.321 \\
\hline & $(0.006)$ & $(0.007)$ & $(0.008)$ \\
\hline \multirow[t]{2}{*}{$\sigma_{\eta}$} & 0.34 & 0.34 & 0.341 \\
\hline & $(0.009)$ & $(0.01)$ & $(0.011)$ \\
\hline $\begin{array}{l}\text { Log likelihood } \\
N=663\end{array}$ & -3953 & -3936 & -3829 \\
\hline
\end{tabular}


Table 4: Estimates by gender

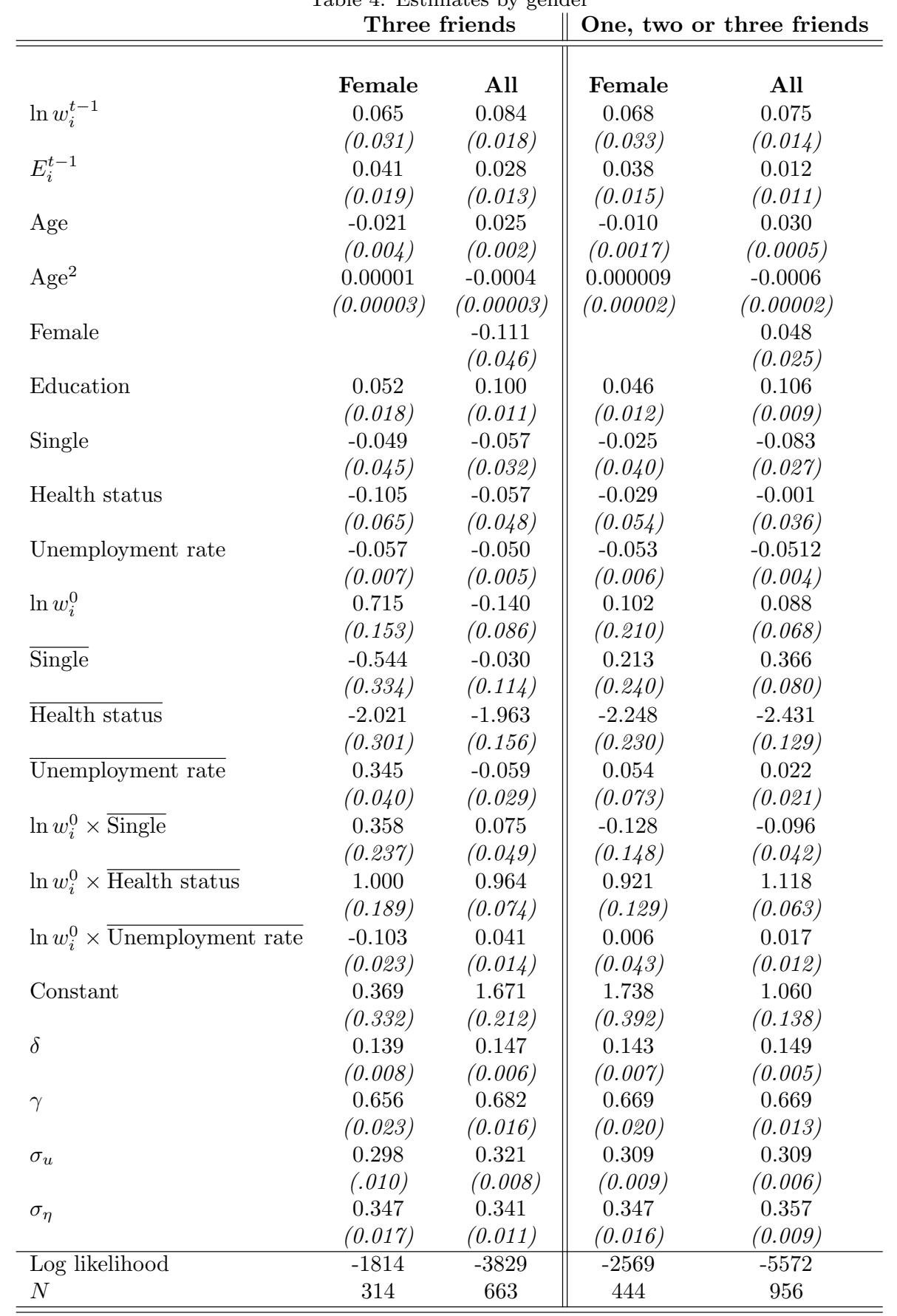


Table 5: Joint model of the number of employed friends and wage dynamics

\begin{tabular}{|c|c|c|c|}
\hline & $\ln w_{i}^{t}$ & & $E_{i}^{t}$ \\
\hline $\ln w_{i}^{t-1}$ & $\begin{array}{c}0.071 \\
(0.029)\end{array}$ & $\ln w_{i}^{t-1}$ & $\begin{array}{c}0.236 \\
(0.054)\end{array}$ \\
\hline$E_{i}^{t-1}$ & $\begin{array}{c}0.056 \\
(0.018)\end{array}$ & $E_{i}^{t-1}$ & $\begin{array}{c}0.631 \\
(0.048)\end{array}$ \\
\hline Age & $\begin{array}{c}0.005 \\
(0.002)\end{array}$ & Unemployment rate & $\begin{array}{c}0.014 \\
(0.013)\end{array}$ \\
\hline $\mathrm{Age}^{2}$ & $\begin{array}{c}-0.0003 \\
(0.00002)\end{array}$ & $a_{0}$ & $\begin{array}{l}-0.580 \\
(0.200)\end{array}$ \\
\hline Education & $\begin{array}{c}0.047 \\
(0.012)\end{array}$ & $a_{1}$ & $\begin{array}{c}0.693 \\
(0.189)\end{array}$ \\
\hline Single & $\begin{array}{l}-0.024 \\
(0.044)\end{array}$ & $a_{2}$ & $\begin{array}{c}2.190 \\
(0.186)\end{array}$ \\
\hline Health status & $\begin{array}{l}-0.113 \\
(0.068)\end{array}$ & $\sigma_{\nu}$ & $\begin{array}{c}0.337 \\
(0.016)\end{array}$ \\
\hline Unemployment rate & $\begin{array}{l}-0.056 \\
(0.007)\end{array}$ & $\rho$ & $\begin{array}{l}-0.649 \\
(0.589)\end{array}$ \\
\hline$\delta$ & $\begin{array}{c}0.139 \\
(0.008)\end{array}$ & & \\
\hline$\gamma$ & $\begin{array}{c}0.658 \\
(0.023)\end{array}$ & & \\
\hline$\sigma_{u}$ & $\begin{array}{c}0.298 \\
(0.009)\end{array}$ & & \\
\hline Constant & $\begin{array}{c}1.971 \\
(0.271)\end{array}$ & & \\
\hline$\overline{\text { Single }}$ & $\begin{array}{l}-0.688 \\
(0.243)\end{array}$ & & \\
\hline$\overline{\text { Health status }}$ & $\begin{array}{l}-1.696 \\
(0.402)\end{array}$ & & \\
\hline$\overline{\text { Unemployment rate }}$ & $\begin{array}{c}0.018 \\
(0.046)\end{array}$ & & \\
\hline $\ln w_{i}^{0}$ & $\begin{array}{l}-0.259 \\
(0.154)\end{array}$ & & \\
\hline $\ln w_{i}^{0} \times \overline{\text { Single }}$ & $\begin{array}{c}0.436 \\
(0.118)\end{array}$ & & \\
\hline $\ln w_{i}^{0} \times \overline{\text { Health status }}$ & $\begin{array}{c}0.853 \\
(0.189)\end{array}$ & & \\
\hline $\ln w_{i}^{0} \times \overline{\text { Unemployment rate }}$ & $\begin{array}{c}0.046 \\
(0.026)\end{array}$ & & \\
\hline$\sigma_{\alpha}$ & $\begin{array}{c}0.601 \\
(0.422)\end{array}$ & & \\
\hline Log likelihood & -3843 & $N$ & 314 \\
\hline
\end{tabular}

